\title{
Synchronous Variability in the Southern Hemisphere Atmosphere, Sea Ice, and Ocean Resulting from the Annular Mode*
}

\author{
Alex Hall \\ Department of Atmospheric Sciences, University of California, Los Angeles, Los Angeles, California \\ MARTIN VISBECK \\ Lamont-Doherty Earth Observatory, Columbia University, Palisades, New York
}

(Manuscript received 23 October 2001, in final form 11 April 2002)

\begin{abstract}
Zonally symmetric fluctuations of the midlatitude westerly winds characterize the primary mode of atmospheric variability in the Southern Hemisphere during all seasons. This is true not only in observations but also in an unforced 15 000-yr integration of a coarse-resolution (R15) coupled ocean-atmosphere model. Here it is documented how this mode of atmospheric variability, known as the Southern Annular Mode (SAM), generates ocean circulation and sea ice variations in the model integration on interannual to centennial timescales that are tightly in phase with the SAM. The positive phase of the SAM is associated with an intensification of the surface westerlies over the circumpolar ocean (around $60^{\circ} \mathrm{S}$ ), and a weakening of the surface westerlies farther north. This induces Ekman drift to the north at all longitudes of the circumpolar ocean, and Ekman drift to the south at around $30^{\circ} \mathrm{S}$. Through mass continuity, the Ekman drift generates anomalous upwelling along the margins of the Antarctic continent, and downwelling around $45^{\circ} \mathrm{S}$. The anomalous flow diverging from the Antarctic continent also increases the vertical tilt of the isopycnals in the Southern Ocean, so that a more intense circumpolar current is also closely associated with positive SAM. In addition, the anomalous divergent flow advects sea ice farther north, resulting in an increase in sea ice coverage. Finally, positive SAM drives increases in poleward heat transport at about $30^{\circ} \mathrm{S}$, while decreases occur in the circumpolar region. Ocean and sea ice anomalies of the opposite sign occur when the SAM is negative. The ocean and sea ice fluctuations associated with the SAM constitute a significant fraction of simulated ocean variability poleward of $30^{\circ} \mathrm{S}$ year-round. The robustness of the mechanisms relating the SAM to oceanic variability suggests that the SAM is likely an important source of large-scale variability in the real Southern Hemisphere ocean.
\end{abstract}

\section{The atmospheric jet stream and Southern Hemisphere geography}

If the earth's surface were perfectly uniform, the temperature response to the zonally symmetric equator-topole gradient in solar forcing would also be zonally symmetric. This would generate, in turn, a midlatitude jet stream with zonally symmetric statistics of variability. Of course, the earth's surface is not uniform. In the Northern Hemisphere $(\mathrm{NH})$, there are large zonal contrasts in surface type. In crude terms, there are two north-south-oriented strips of ocean interrupted by two strips of land. These zonal asymmetries set up the wellknown wavenumber- 2 stationary wave pattern in the

* Lamont-Doherty Earth Observatory Contribution Number 6363.

Corresponding author address: Dr. Alex Hall, Dept. of Atmospheric Sciences, UCLA, 7955 Math Sciences Building, 405 Hilgard Ave., Box 951565, Los Angeles, CA 90095.

E-mail: alexhall@atmos.ucla.edu climatological mean state of the NH jet stream. [Broccoli and Manabe (1992), by comparing atmospheric simulations with and without mountains, provide evidence that orography is the main reason for these stationary undulations of the NH jet stream.] Because of the wavenumber-2 pattern, the most baroclinically unstable parts of the jet stream are concentrated over the North Atlantic and Pacific, giving rise to the NH Atlantic and Pacific storm tracks.

Just as the zonal contrasts in $\mathrm{NH}$ geography disrupt the zonal symmetry in the $\mathrm{NH}$ jet stream, the relative zonal uniformity of Southern Hemisphere (SH) geography reinforces the zonal symmetry of the SH midlatitude atmospheric jet stream: Directly over the South Pole sits a permanently frozen continent topped with a glacier a few kilometers thick. This continent is surrounded by an ocean extending more than halfway to the equator. Relatively small landmasses interrupt the zonal symmetry farther north, but the surface area all the way to the equator is overwhelmingly dominated by ocean. The large thermal contrast between the polar 
continent and the tropical ocean generates an intense jet stream that is much more zonally symmetric than its $\mathrm{NH}$ counterpart.

Just as the jet stream is the dominant feature of the midlatitude atmospheric circulation, it also dominates the signatures of variability. For example, if one examines the mode of atmospheric pressure variability that accounts for the most variance using techniques such as EOF analysis, one sees a clear out-of-phase relationship between pressure over the Pole and pressure in midlatitudes. The ringlike character of this pattern has given rise to the term "annular mode" to refer to the vacillations of the jet stream in both hemispheres (see Thompson and Wallace 2000). The concept of an annular mode also derives from an idealized picture of an atmosphere overlying a completely uniform surface. In atmospheric models with no orography or land-sea contrast, the oscillation of mass associated with jet stream variability is perfectly zonally symmetric and ringlike (James and James 1992; Yu and Hartmann 1993; Lee and Feldstein 1996; Robinson 1996).

All evidence indicates that these turbulent fluctuations of the jet stream can be generated entirely by the atmosphere. For example, using an atmosphere-only general circulation model with seasonally varying sea surface temperatures, Limpasuvan and Hartmann (2000) obtain annular modes in both hemispheres that are nearly identical to observations. Furthermore, numerous researchers (DeWeaver and Nigam 2000a,b; Limpasuvan and Hartmann 2000, 1999; Hartmann and Lo 1998) have diagnosed the internal atmospheric dynamics responsible for the annular mode: Both hemispheres' jet streams are substantially modified by the synoptic-scale eddies they spawn, giving rise to mutually reinforcing feedbacks between eddies and the mean flow. An anomaly in the jet stream generates anomalous eddy activity of the same sign, which in turn strengthens the jet stream anomaly through eddy momentum fluxes. The vacillations of the jet stream are then largest where eddy activity is largest. Because of the zonal asymmetries of NH geography, eddy activity and consequently jet stream variability is largest in the Atlantic and Pacific storm track regions. So the anticorrelation between midand high-latitude atmospheric pressure that is the hallmark of the annular mode is strongest in the Atlantic and Pacific sectors. In the $\mathrm{SH}$, because of its relative zonal symmetry, eddy activity is much more evenly distributed among all longitudes. This, in turn, gives rise to an annular mode that is much more zonally symmetric than its $\mathrm{NH}$ counterpart (Thompson and Wallace 2000). That eddy-mean flow interactions are key to understanding the annular mode is also suggested by the fact that the annular modes in both hemispheres exhibit little variability on timescales shorter than the synoptic eddy timescale. For example, Hartmann and Lo (1998) show that the $e$-folding timescale of the autocorrelation of the observed Southern Hemisphere annular mode (SAM) index is approximately 10 days.
The SAM is different from its NH counterpart (NAM) not only in its much higher degree of zonal symmetry, but also in its relatively weak seasonal variability, which reflects the relatively weak seasonality of the equatorto-pole temperature gradient and atmospheric jet stream. Hartmann and Lo (1998) found that the SAM weakens somewhat in the summertime but retains its structure in both observations and an atmospheric model simulation. This is in contrast to the NAM, which practically disappears in summertime.

In this study, we focus not on the internal atmospheric dynamics of the SAM, but on the implications of a highly zonally symmetric and year-round mode of atmospheric variability for the rest of the SH climate system, in particular, sea ice and the ocean. While the relatively high degree of zonal symmetry of SH geography reinforces the zonally symmetric character of the primary mode of internal atmospheric variability (i.e., the annular mode), it also facilitates hemispheric-scale synchronization of ocean variability with annular mode forcing. Even if by some improbable mechanism the NAM were perfectly zonally symmetric in spite of the zonal asymmetries of $\mathrm{NH}$ geography, the response of the NH oceans to this forcing could never be zonally symmetric or coherent between ocean basins, both because of the huge differences in geometry between the ocean basins and their physical separation. In the $\mathrm{SH}$, on the other hand, very little land exists at the latitudes where annular mode variability is strongest. This, coupled with the relative zonal symmetry of the annular mode forcing itself, sets up very favorable conditions for atmosphere-ocean covariability: when the SAM is in its positive phase, surface westerlies strengthen at all longitudes of the circumpolar ocean, and the ocean has to respond in a similar way at all longitudes, creating a coherent, zonally symmetric ocean mode of variability tightly in phase with the SH annular mode. In this study, we show that much of the variability throughout the entire $\mathrm{SH}$ ocean poleward of $30^{\circ} \mathrm{S}$ in a coupled oceanatmosphere model simulation can be linked directly to the SAM.

These results lead us to a new perspective on internal climate variability in the mid-to high latitudes of the $\mathrm{SH}$. Adopting the view of a synchonously varying, zonally symmetric system from the top of the atmosphere down to the ocean bottom is useful because it probably captures a good deal of the variability in this region. Of course, this hypothesis must be tested against the observational record to be fully validated. However, the simulated SAM is realistic enough and the mechanisms we identify relating the SAM to ocean variability are robust enough that it seems likely the observed record will reveal similar results to this simulation. Few hypotheses for what causes $\mathrm{SH}$ climate variability have been proposed. In fact, the mid- to high latitudes of the $\mathrm{SH}$ remains a critical blind spot in our understanding of the global climate system from both theoretical and observational perspectives. The ideas presented in this 

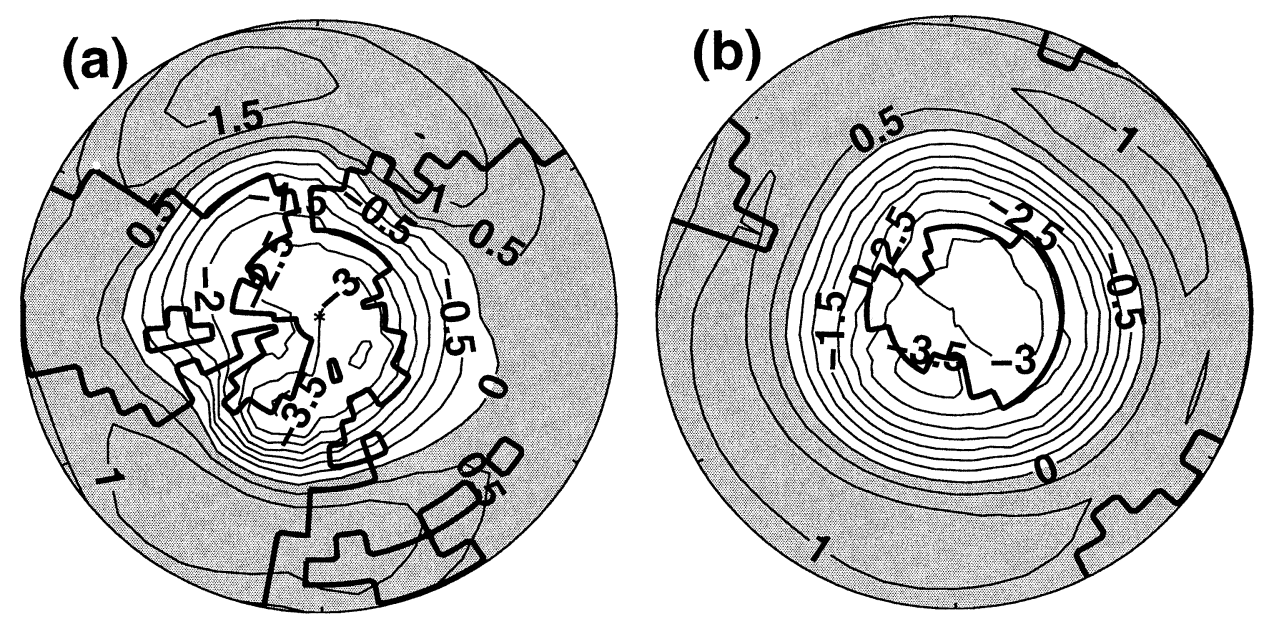

FIG. 1. (a) The pattern associated with the first EOF of variability for NH DJF seasonal mean surface pressure data poleward of $9^{\circ} \mathrm{N}$. This pattern accounts for $24 \%$ of the variance. (b) Same as (a), except for SH JJA seasonal mean surface pressure data poleward of $9^{\circ} \mathrm{S}$. This pattern accounts for $34 \%$ of the variance. The surface pressure fields were area weighted prior to the computation of the EOFs. Positive areas are gray, while negative areas are white. This convention is observed in all subsequent figures. Units are $\mathrm{hPa}$.

paper therefore constitute a significant, though preliminary, step forward.

We begin by describing the coupled model simulation (section 2) and the annular modes it produces (section 3 ). Then in section 4, we describe and document the mechanism that links the SAM to SH ocean circulation variability, followed by a description of its associated impacts on other features of the ocean, such as heat transport, SST, and sea ice (section 5). Finally, we discuss the possible implications of these results for $\mathrm{SH}$ climate in section 7 .

\section{Model description}

To study the role of the SAM in SH sea ice and ocean variability on interannual to centennial timescales, we examine the variability in the middle $5000 \mathrm{yr}$ of a 15 000-yr integration of a coupled ocean-atmosphere model. What follows is a brief description of this model. It is described in greater detail in Manabe et al. (1991). The model has a global domain with geography as realistic as possible given its computational resolution (see the depictions of model geography in Fig. 1). The atmospheric component has nine vertical levels, with horizontal distributions of atmospheric variables represented by spherical harmonics and gridpoint values with $4.5^{\circ}$ latitude by $7.5^{\circ}$ longitude spacing (Gordon and Stern 1982). Sunshine varies seasonally, but not daily. Cloud cover is predicted based on relative humidity. A land surface model computes surface fluxes of heat and water. Continental ice sheets are prescribed. The ocean component (Bryan and Lewis 1979) employs a full finite-difference technique and has a regular grid system with approximately $4.5^{\circ}$ latitude by $3.8^{\circ}$ longitude spacing. There are 12 vertical levels in the ocean. The effects of mesoscale eddies are represented by diffusion of po- tential temperature and salinity on constant density surfaces. The model also has some diapycnal diffusion for numerical stability. A sea ice model is also included (Bryan 1969). It computes sea ice thickness based on thermodynamic heat balance. Advection of ice by ocean currents is also included, so long as the ice thickness is less than $4 \mathrm{~m}$. When the ice thickness if greater than 4 $\mathrm{m}$, divergent ice flow with surface currents is allowed, but convergent flow is not. This is meant to mimick the inability of ocean currents to transport sea ice into regions where the ice pack is already very thick. The atmospheric and oceanic components exchange heat, water, and momentum once a day.

The coupled model's quasi-equilibrium initial condition is obtained by separate integrations of the atmospheric and oceanic components using observed surface boundary conditions [sea surface temperature (SST), sea surface salinity (SSS), and sea ice thickness]. When the integration of the coupled model begins from this initial condition, the simulated climate drifts toward a less realistic equilibrium state. To reduce drift, the fluxes of heat and water at the ocean-atmosphere interface are adjusted by given amounts before they are imposed on the ocean surface. The flux adjustments are determined prior to the coupled model run from separate integrations of the atmosphere and ocean models. They do not change from one year to the next and are independent of the SST and SSS anomalies that develop during the simulation. Thus they neither damp nor amplify these anomalies in any systematic way. Although the adjustments do not eliminate the shortcomings of the model (Marotzke and Stone 1995), they do help prevent rapid drift from the initial state. Such drift can seriously distort the internal climate variability that is the subject of this study.

Although this model's resolution is coarse, and its 
parameterizations are not complicated, it is very computationally efficient, allowing for very long integrations, such as the $15000-y r$ run we analyze in this paper. This is the longest coupled model experiment in existence as of the writing of this paper, and its extraordinary length has two advantages. First, it allows for analysis of very low frequency climate variability. (See, e.g., the results for centennial and longer timescales presented in Fig. 7.) Second, it makes for extraordinarily trustworthy statistics. For example, in this study, we analyze $5000 \mathrm{yr}$ of data. Suppose one examines the correlation between 5000-yr-long, annual-mean time series of two different model variables. For all correlations greater in magnitude than 0.03 , the probability that no relationship exists between the two time series would be less than $1 \%$. So the $99 \%$ "significance level" for such a long time series is essentially zero.

\section{Simulation of annular modes}

To assess the realism of the model's simulation of annular modes, we examined the leading mode of the model's surface pressure field in both hemispheres. In keeping with convention, we restricted our analysis to wintertime, when the jet stream and storm tracks are at their peak. In the NH (Fig. 1a), the leading mode is characterized by an out-of-phase relationship between surface pressure over the Arctic and surface pressure in the North Atlantic and Pacific, as is the case with the observed leading mode (see Fig. 3d of Thompson and Wallace 2000). In the North Atlantic sector, the NAM resembles the observed closely, with the nodes of the simulated and observed patterns both located at about $55^{\circ} \mathrm{N}$. In the North Pacific sector, the simulated and observed are less similar in that the node of the simulated pattern lies at about $55^{\circ} \mathrm{N}$, while the node in the observed pattern lies farther north, at about $60^{\circ} \mathrm{N}$. In addition, the North Pacific lobe of the model's pattern is more pronounced than the Atlantic lobe. The opposite is true in observations.

In the SH (Fig. 1b), a clear out-of-phase relationship between surface pressure in mid- and high latitudes is also apparent. Like the observed (see Fig. 3c of Thompson and Wallace 2000), the SH pattern is much more zonally symmetric than in its NH counterpart and its node lies directly over the center of the circumpolar ocean at about $55^{\circ} \mathrm{S}$. In both the $\mathrm{NH}$ and $\mathrm{SH}$, the model's annular mode is similar to the observed. In spite of its coarse computational resolution, the model can resolve the eddies whose interaction with the mean flow generates the annular modes. This is consistent with the findings of Manabe and Hahn (1981). Analyzing a simulation employing only the atmospheric component of this model, they found that it approximately reproduces the observed magnitude of daily, monthly, and annualmean surface pressure variability in mid- to high latitudes. This indicates the atmospheric model has a realistic amount of eddy activity.
In section 1 , we noted that while the NAM practically disappears during summertime, the SAM remains the dominant feature of variability throughout the year in both observations and an atmospheric model similar in structure to the model we analyze but with double the resolution (Limpasuvan and Hartmann 2000). Examining the dominant mode of pressure variability for all four seasons (Fig. 2), it is clear that this coarse-resolution model exhibits the same behavior. The pattern is very ringlike all year-round, with the positive phase associated with a low over the Pole, and a high in midlatitudes. The intensity of the modes increases slightly during the cold months, consistent with the slight intensification of the equator-to-pole temperature gradient.

Because of the relatively weak seasonality of the simulated SAM, we will examine its role in forcing ocean variability from an annual-mean perspective. We constructed a time series of the dominant mode of annualmean pressure variability by performing EOF analysis on annual-mean surface pressure data. We will be correlating and regressing annual-mean ocean variables with this time series to illuminate the relationships between the SAM and ocean variability. Not surprisingly, the pattern associated with this time series (not shown) very closely resembles the patterns seen in Fig. 2. It also accounts for a similar amount of the total variance: $39 \%$. This is a large fraction of the variability, especially in view of the fact that the domain included in the EOF analysis extends to $9^{\circ} \mathrm{S}$, where a significant proportion of surface pressure variability is unlikely to be directly related to the variability of the midlatitude jet stream. A comparable amount of variability (about 30\%) is attributable to the SAM in the real climate (D. Thompson 2002, personal communication).

Because of the strong zonal symmetry of the SAM throughout the year, taking a zonal-mean perspective can provide a concise means of conveying information about its behavior. To provide a brief overview of the behavior of the SAM in the model atmosphere, we show the vertical structure of zonal-mean zonal, meridional, and vertical velocity anomalies associated with the positive phase of the SAM throughout the atmosphere (Fig. 3). From about $45^{\circ}$ to $75^{\circ} \mathrm{S}$, positive SAM implies intensification of the westerly winds (Figs. 3a,b) throughout the model atmosphere. From $45^{\circ}$ to $20^{\circ} \mathrm{S}$, on the other hand, easterly anomalies occur when the SAM is positive. This is consistent with a poleward shift of the atmospheric jet stream. This is also the pattern seen in observations (see Fig. 3a of Thompson and Wallace 2000). Anomalies in the meridional winds are also seen (Figs. 3c,d). The main features are poleward flow due to friction from the westerly anomaly from $45^{\circ}$ to $75^{\circ} \mathrm{S}$, and equatorward frictional flow stemming from the easterly anomaly from $45^{\circ}$ to $20^{\circ} \mathrm{S}$. Figures 3e,f demonstrate that positive SAM is associated with subsidence throughout the mid- and lower atmosphere from $55^{\circ}$ to $35^{\circ} \mathrm{S}$, and rising motion throughout the mid- and lower atmosphere from $55^{\circ}$ to $80^{\circ} \mathrm{S}$. This is likely due to the 

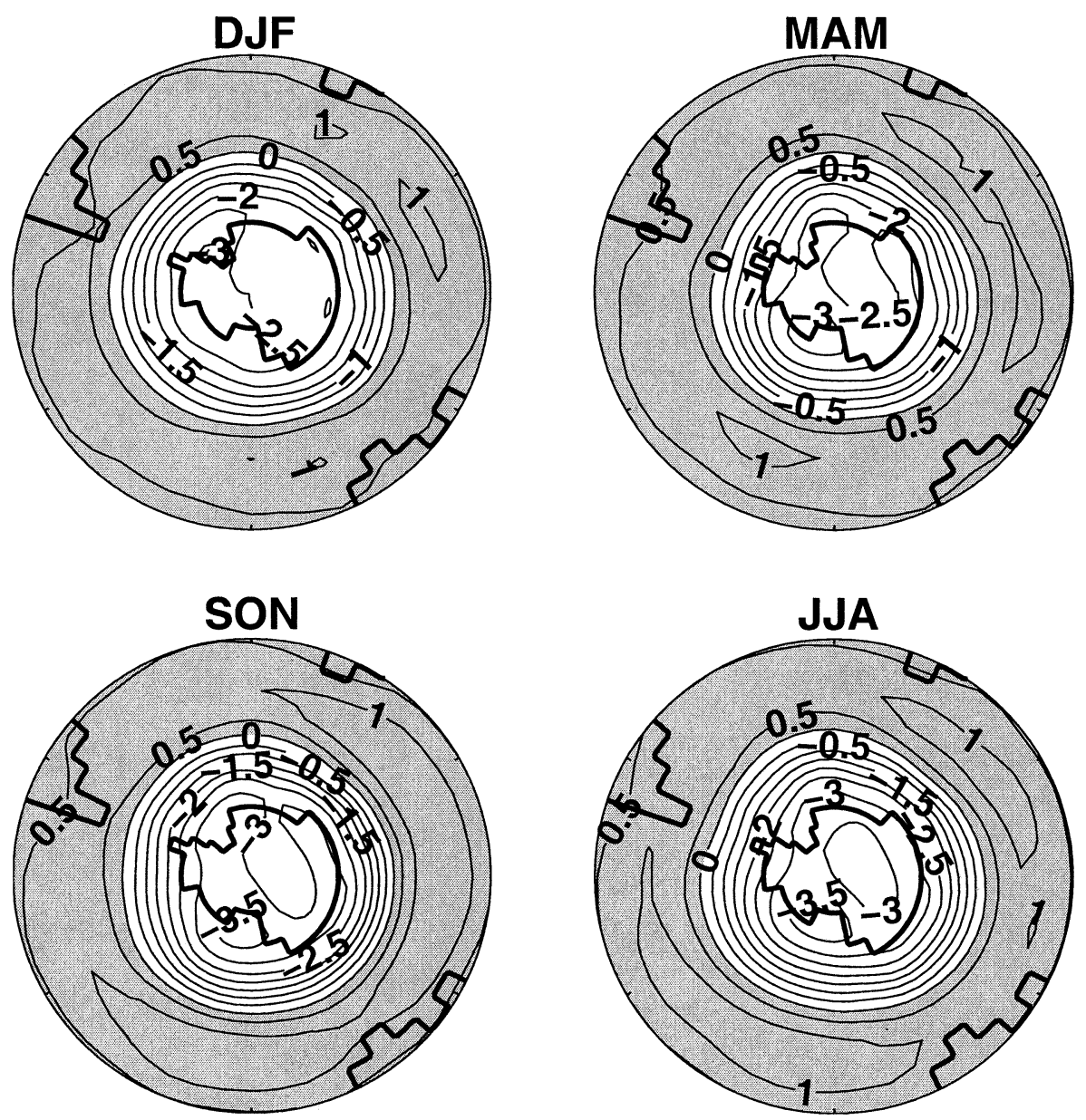

FIG. 2. The patterns associated with the first EOFs of surface pressure (hPa) variability for all four seasons in the SH. All surface pressure data poleward of $9^{\circ} \mathrm{S}$ are included in the EOF computation. For DJF, MAM, JJA, and SON, the patterns shown account for $39 \%, 30 \%, 34 \%$, and $24 \%$, of the variance, respectively. Note that Fig. 1b is identical to the panel marked JJA in this figure.

divergent meridional flow at the surface around $45^{\circ} \mathrm{S}$, and the convergent meridional flow near the Pole. In addition, the poleward movement of the jet stream and associated eddy activity may enhance rising motion north of $55^{\circ} \mathrm{S}$ and reduce it south of that point.

\section{Covariability in the atmosphere and ocean}

In the previous section, we discussed how much of the variability of the simulated and real atmosphere in the mid- to high latitudes of the SH is attributable to the SAM. In this section, we examine the extent to which ocean variability can be related to the SAM. As outlined in section 1, there are reasons to expect covariability between the SAM and the ocean circulation.

To understand how the SAM affects SH ocean variability, we must first understand how the atmosphere influences the mean state of the SH ocean. The high degree of zonal symmetry of SH geography is largely responsible for the peculiar state of the ocean in this region (Gill and Bryan 1971). In the real and simulated worlds, surface westerly winds prevail in much of the circumpolar ocean region (Fig. 4a). This drives Ekman drift to the north at all longitudes, creating divergent surface flow away from the Antarctic continent. This divergent flow prevents warm waters from reaching the circumpolar region, accentuating the isolation of the Antarctic continent. The inability of warm water to penetrate to higher latitudes in the SH sets up an extremely sharp density gradient between the waters near the Antarctic continent and the waters north of the Drake Passage. This density gradient, in turn, drives the intense eastward circumpolar current. The simulated surface manifestation of this current is shown in Fig. 5a. The relative zonal asymmetry of $\mathrm{NH}$ geography makes for a vivid contrast between the ocean circulations of the two hemispheres: in the $\mathrm{NH}$, the presence of northsouth-oriented continental margins in midlatitudes, where surface westerlies dominate, results in the development of western boundary currents rather than a circumpolar current.

Since fluctuations of the surface westerlies are a fea- 


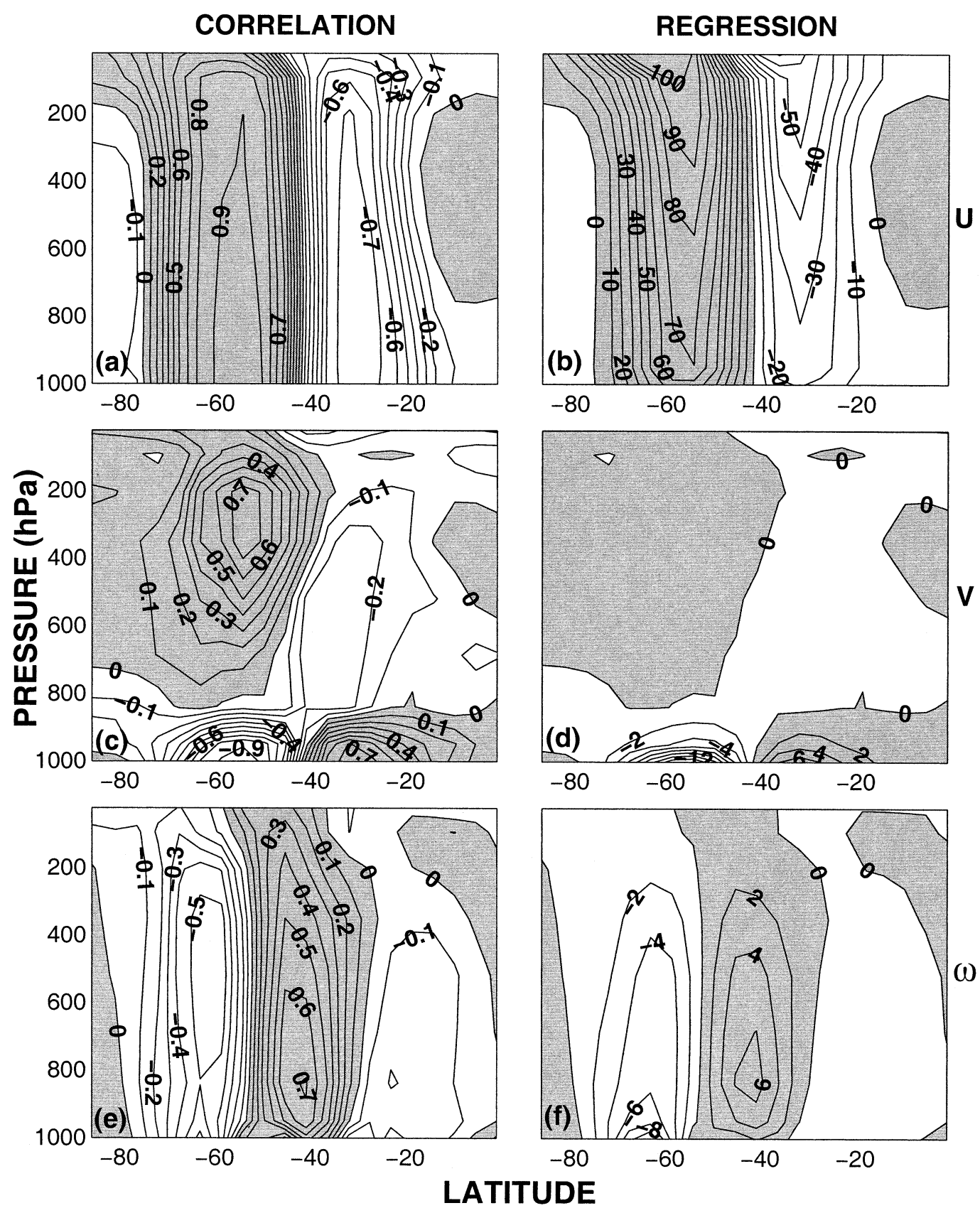

FIG. 3. (a), (c), (e) Correlation and (b), (d), (f) regression coefficients between annual-mean, zonally averaged zonal, meridional, and vertical winds throughout the atmosphere and the annual-mean SAM index. Since the SAM index is dimensionless with unit variance, units of the regression coefficients are the same as the units of the winds themselves: $\mathrm{cm} \mathrm{s}^{-1}$ for $U$ and $V$ and $10^{-6} \mathrm{hPa} \mathrm{s}^{-1}$ for $\omega$.

ture of the SAM, and since these same surface westerlies are responsible for the large-scale features of the $\mathrm{SH}$ ocean circulation (i.e., divergence away from the Antarctic continent and the circumpolar current), it makes intuitive sense that the SAM would generate variability in these features of the ocean circulation. At the surface, positive SAM manifests itself as a poleward migration of the mean westerly winds. A one sigma positive SAM anomaly implies about a $10 \%$ intensification of the westerly wind stress in the circumpolar ocean region, and a weakening of the westerly wind stress farther north (Fig. 4b). As suggested by Fig. 4c, these anomalies account for a very large amount of the overall wind stress variability; in most portions of the circumpolar ocean, the correlation between the SAM index and the zonal wind stress exceeds 0.6. Farther north, the anticorrelation be- 

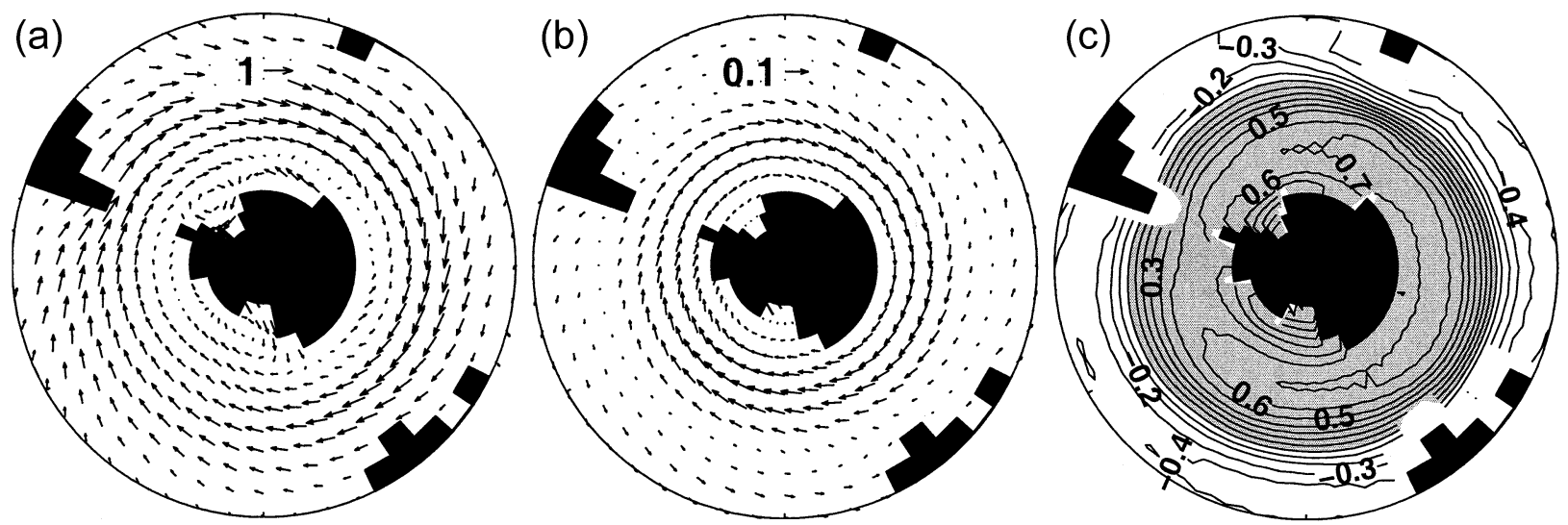

FIG. 4. (a) The annual-mean climatological wind stress imposed on the ocean by the model atmosphere in the circumpolar region. (b) The regression of annual-mean wind stress onto the annual-mean SAM index. Regressions for the zonal and meridional components of the wind stress were calculated separately. Units for (a) and (b) are dyn $\mathrm{cm}^{-2}$. For clarity, every other arrow in each latitude row is suppressed in (a) and (b). Arrows illustrating the scaling of the vectors are shown in the top middle of the panels. (c) The correlation between the zonal component of the annual-mean wind stress and the annual-mean SAM index.

tween the zonal wind stress and the SAM is also large, dipping below -0.4 in many areas.

How then do these wind stress anomalies affect the ocean circulation? In the circumpolar region, where positive SAM implies intensification of the westerly winds, flow mainly to the north occurs (Fig. 5b). Farther north, where westerlies weaken, southward flow results. These current anomalies are very similar to those that would result if the wind stress pattern associated with positive SAM resulted only in Ekman drift in the 50-m-deep first layer of the model ocean (Fig. 5d). This indicates that the current anomalies of Fig. 5b can be directly related to the wind stress through the Ekman mechanism. There are, however, hints of disagreement between Figs. 5b and $5 \mathrm{~d}$. For example, in the circumpolar region, the current anomalies of Fig. 5b are generally tilted slightly more to the east. As we discuss below, this can be related to intensification of the circumpolar current. Examination of the correlation between meridional ocean currents and the SAM index (Fig. 5c) reveals that the current anomalies of Fig. $5 b$ represent a very significant fraction of surface current variability. The correlations in the circumpolar ocean exceed 0.6 in many regions.

We have shown that the SAM has a very direct and significant effect on simulated surface current variability in the Southern Ocean. What about the rest of the Southern Ocean, which is not in such close contact with the atmosphere? The zonal symmetry of the surface current response to the SAM indicates that information about ocean response to the SAM is not lost by taking a zonalmean perspective. Figure 6 summarizes the relationship between the zonal-mean meridional and vertical ocean flow throughout the Southern Hemisphere. Consistent with Figs. 5b and 5c, Figs. 6a and 6c show that the SAM is very significantly correlated with northward surface flow between $45^{\circ}$ and $70^{\circ} \mathrm{S}$, and southward surface flow from about $20^{\circ}$ to $40^{\circ} \mathrm{S}$. This results in convergence and downwelling near $45^{\circ} \mathrm{S}$, and divergence and upwelling near the Antarctic continent at about $60^{\circ} \mathrm{S}$ (Figs. $6 \mathrm{~b}$ and $6 \mathrm{c}$ ). The vertical motion penetrates nearly to the bottom of the ocean and is highly correlated with the SAM index to depths of 2-3000 m.

Return flow at depth must balance the surface meridional flow anomalies. If the model ocean bottom were flat, one would expect the return flow to be confined to a turbulent frictional layer at the ocean bottom. Because of the model's coarse resolution, its bottom topography is relatively smooth, varying between 3000 and 4500 $\mathrm{m}$ over most of the circumpolar region. Accordingly, the simulated return flow (most evident in Fig. 6a) resembles what would be expected from a flat bottom ocean. With higher resolution and more realistic bottom topography, the surface meridional flow anomalies would very likely still occur. However, rather than being confined to a turbulent frictional layer at the bottom, significant return flow at depth could be supported geostrophically through zonal pressure differences across topography. This return flow would reflect the complexity of the real ocean's bottom relief, and would perhaps be more evenly distributed throughout the ocean. This implies that the pattern in Fig. 6a would likely change with resolution, though it also suggests that a significant portion of variability of the deep ocean circulation in this region would be related to the SAM no matter what the model resolution.

Much of the variability in the strength of the circumpolar current ought to be traceable to the SAM as well. As discussed above, the existence of the circumpolar current can be traced partly to the fact that westerly winds generate divergent flow away from the Antarctic continent. So it seems intuitive that the variations in the surface westerlies ought to produce variability in the circumpolar current. Figure 7 confirms this in the simulation. Figure $7 \mathrm{~b}$ shows the coherence between the SAM and the circumpolar current. On timescales between 2 and $25 \mathrm{yr}$, a very significant coherence between 

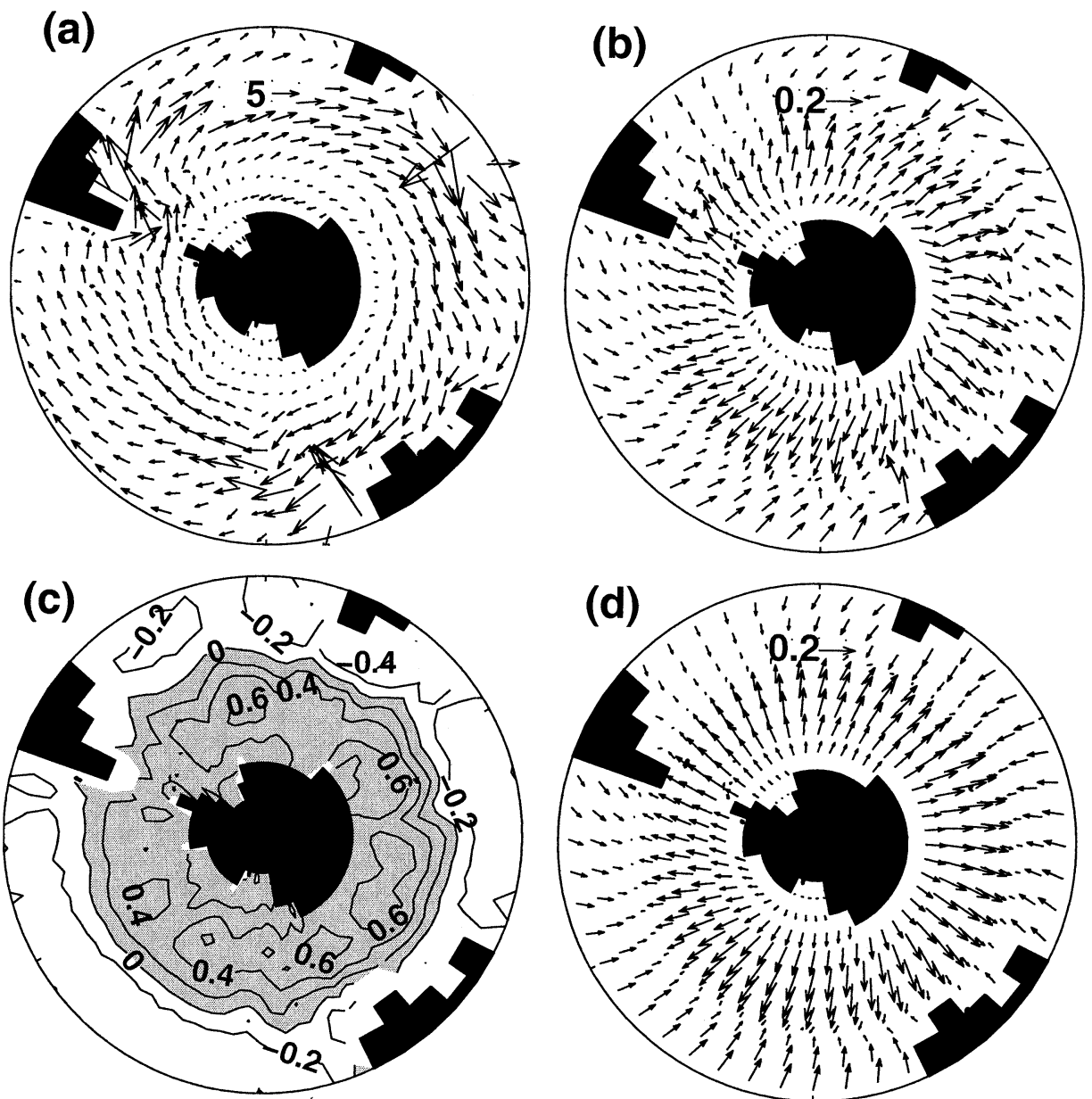

FIG. 5. (a) The annual-mean climatological surface currents simulated by the ocean model. (b) The regression of annual-mean surface currents onto the annual-mean SAM index. Regressions for the zonal and meridional components of the surface currents were calculated separately. (c) The correlation between the meridional component of the annual-mean surface current and the annual-mean SAM index. (d) The Ekman drift that would result if the wind stress pattern shown in Fig. 4b were imposed on the surface layer of the ocean model. Units for (a), (b), and (d) are $\mathrm{cm} \mathrm{s}^{-1}$. For clarity, every other arrow in each latitude row is suppressed. Arrows illustrating the scaling of the vectors are shown in the top middle of (a), (b), and (d).

the SAM and the circumpolar current is observed. The coherence drops off to very low values on timescales between 25 and $150 \mathrm{yr}$.

Though a detailed analysis of the timescale dependence of the coherence between the SAM and the circumpolar current strength is beyond the scope of this paper, preliminary analysis indicates that the drop-off in coherence on the 25-150-yr timescale can be explained by the presence of another mode of variabilitymost likely internal to the ocean-that is most active on these timescales. This is made clearer by an examination of the spectra of the circumpolar current and the SAM index (Fig. 7a). On timescales from 2 to $500 \mathrm{yr}$, the SAM index spectrum is rather white, while the circumpolar current spectrum is very red, with a pronounced hump on timescales of 25-150 yr. The lack of a similar spectral peak in the SAM index, coupled with the lack of coherence between the SAM and the circumpolar current on the 25-150-yr timescale, strongly indicates that another mode of variability exerts primary control on the circumpolar current on these timescales. It should be emphasized that no similar timescale dependence of the relationship between the SAM and meridional and vertical currents is seen (i.e., the statistics presented in Figs. 5 and 6 are practically the same for all resolvable timescales.)

\section{Impact on heat transport, SST, and sea ice}

The strong zonally symmetric projection of meridional ocean current variability onto the SAM (Figs. 5 and 6) suggests the SAM might also have a significant influence on meridional ocean heat transport. To test this, zonal-mean ocean heat transport was calculated at 
(a)

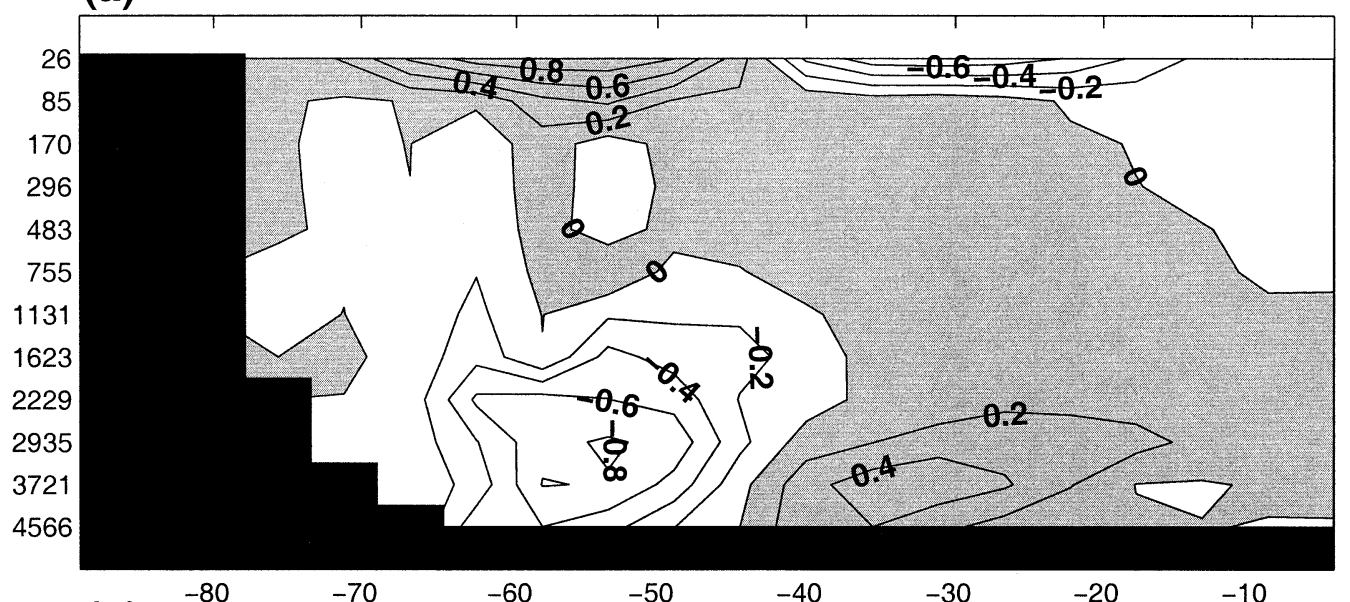

(b)

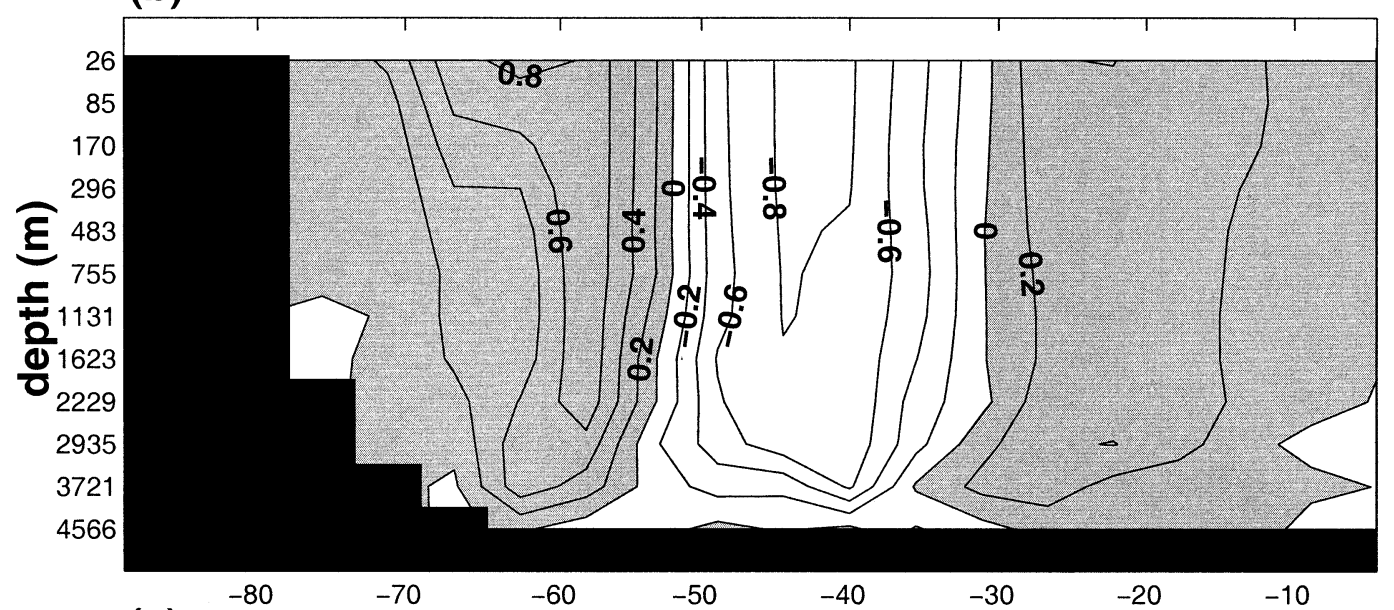

(c)

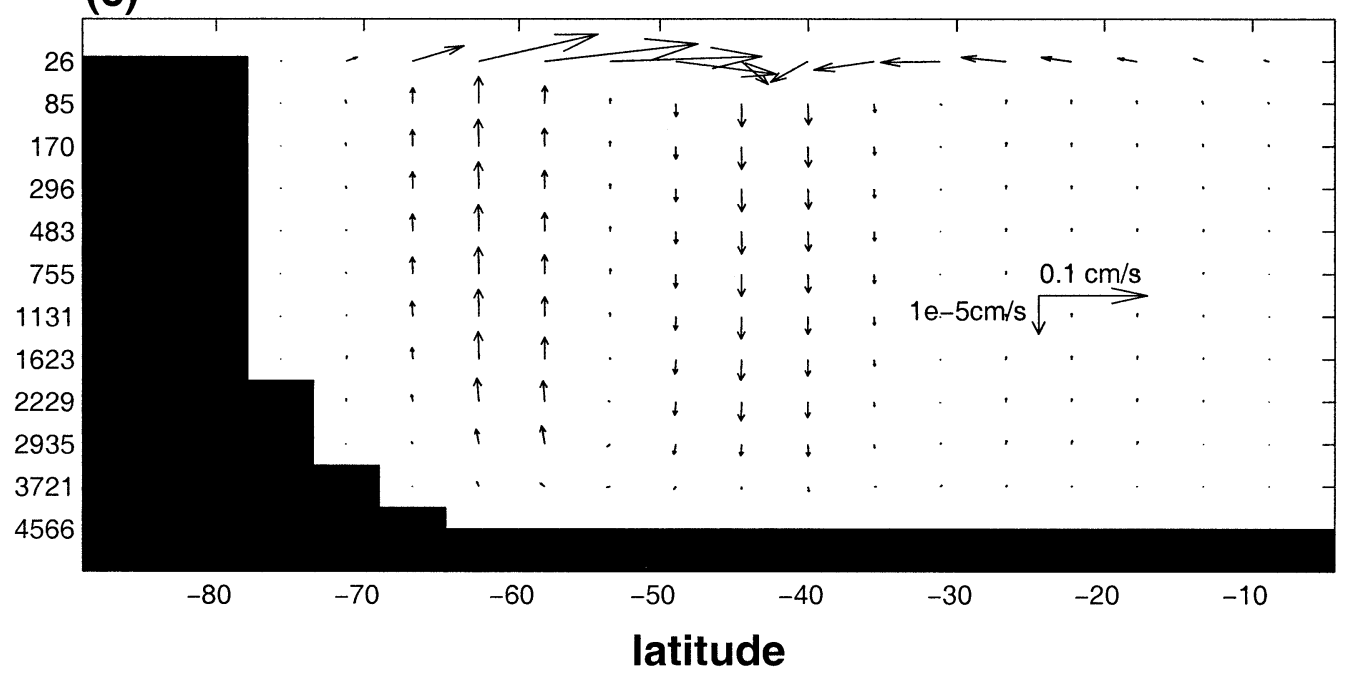

FIG. 6. (a) The correlation between zonal-mean, annual-mean meridional currents throughout the SH ocean and the annualmean SAM index. (b) The correlation between zonal-mean, annual-mean vertical currents throughout the SH ocean and the annual-mean SAM index. (c) The regressions of zonal-mean, annual-mean meridional, and vertical currents onto the annualmean SAM index. Arrows illustrating the scaling of the two components of the vectors are shown at the right. All latitudes and depths with some ocean grid points are depicted as ocean. The topography shown, therefore, does not accurately capture the complexity of the model's bottom topography. 

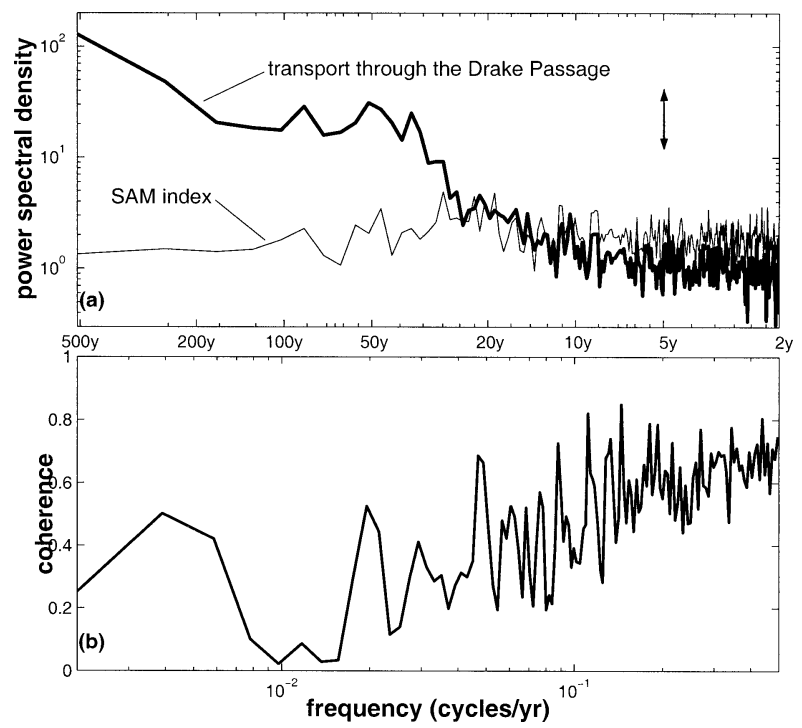

Fig. 7. (a) Spectra of both the circumpolar current, as measured by the annual-mean transport through the Drake Passage, and the annual-mean SAM index. The confidence interval for both spectra is the same, and is shown by the double-headed arrow in the upperright-hand side of the plot. (b) The coherence between the strength of the circumpolar current and the SAM index. Varying between 0 and 1 and analogous to the correlation coefficient, coherence measures the relationship between the two time series as a function of timescale. Timescales in yr are displayed in between (a) and (b).

all latitudes of the SH (Fig. 8a). The model ocean transports heat poleward throughout the $\mathrm{SH}$, with the amount decreasing from a peak of about $1 \mathrm{PW}$ at $15^{\circ} \mathrm{S}$ to $0 \mathrm{PW}$ at $80^{\circ} \mathrm{S}$. Available observations indicate that the real ocean transports a comparable amount of heat (Fig. 8a). The correlation and regression coefficients between the SAM index and the ocean heat transport show particularly significant relationships at about $50^{\circ} \mathrm{S}$, where a reduction in poleward ocean heat transport is associated with positive SAM, and $30^{\circ} \mathrm{S}$, where positive SAM is associated with an increase in poleward heat transport. These anomalies are approximately a tenth as large as the mean heat transport, and are consistent in sign and meridional extent with the surface current anomalies excited by the SAM: during positive SAM, Ekman drift transports cold water northward in the Southern Ocean, thereby reducing poleward heat transport. Likewise, Ekman drift to the south around $30^{\circ} \mathrm{S}$ enhances it.

The heat transport anomalies associated with positive SAM result in a divergence of heat centered at about $55^{\circ} \mathrm{S}$, and a convergence of heat centered at about $40^{\circ} \mathrm{S}$. Since the heat transport anomalies are focused at the surface, this convergence and divergence of heat manifests itself in SST anomalies. The SST anomalies account for a fair amount of the variability in zonal-mean SST (Fig. 9a). Figure 9b demonstrates that for a 1 sigma SAM anomaly, zonal-mean SST decreases in the circumpolar region by about $0.1^{\circ} \mathrm{C}$, while it increases by about $0.05^{\circ} \mathrm{C}$ in the subtropics. These anomalies are fairly small probably because the SST gradients are not
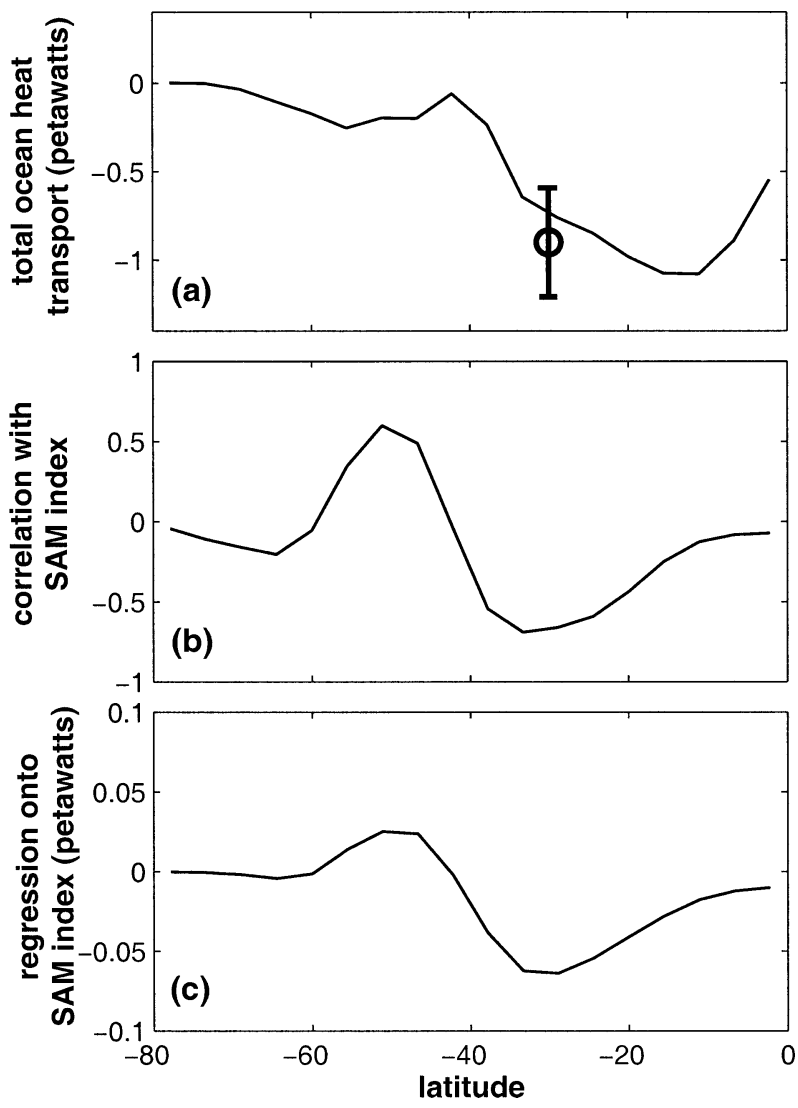

FIG. 8. (a) The annual-mean, zonal-mean simulated ocean heat transport in the SH. Southward heat transport has a negative sign. Also shown, with a circle and associated error bars, is estimated observed ocean heat transport across $30^{\circ} \mathrm{S}$ from MacDonald and Wunsch (1996). (b) The correlation of the annual-mean, zonal-mean ocean heat transport with the annual-mean SAM index. (c) Same as in (b), except regression coefficients are shown.

large in this region, limiting the effect of the current anomalies associated with the SAM on SST. This is not inconsistent with the relatively large impact of the SAM on meridional heat transport since the effect on SST, small though it is, is the same sign at nearly all longitudes.

SST is obviously an important climatic variable. Sea ice is also critical because of its high albedo relative to the open ocean and its role as a thermodynamic buffer between the atmosphere and the ocean. A portion of the current anomaly pattern associated with the SAM (Fig. $5 b)$ lies within the ice-covered regions of the Southern Ocean (Fig. 10a). To the extent that the simulated sea ice distribution is affected by surface currents, one might expect the SAM to force sea ice variability through its forcing of surface currents. The correlation between the SAM index using surface pressure data from the months of June-July-August-September-October-November (JJASON) only and ice thickness during these same months demonstrates this (Fig. 10b). (The JJASON period was chosen because ice extent in 

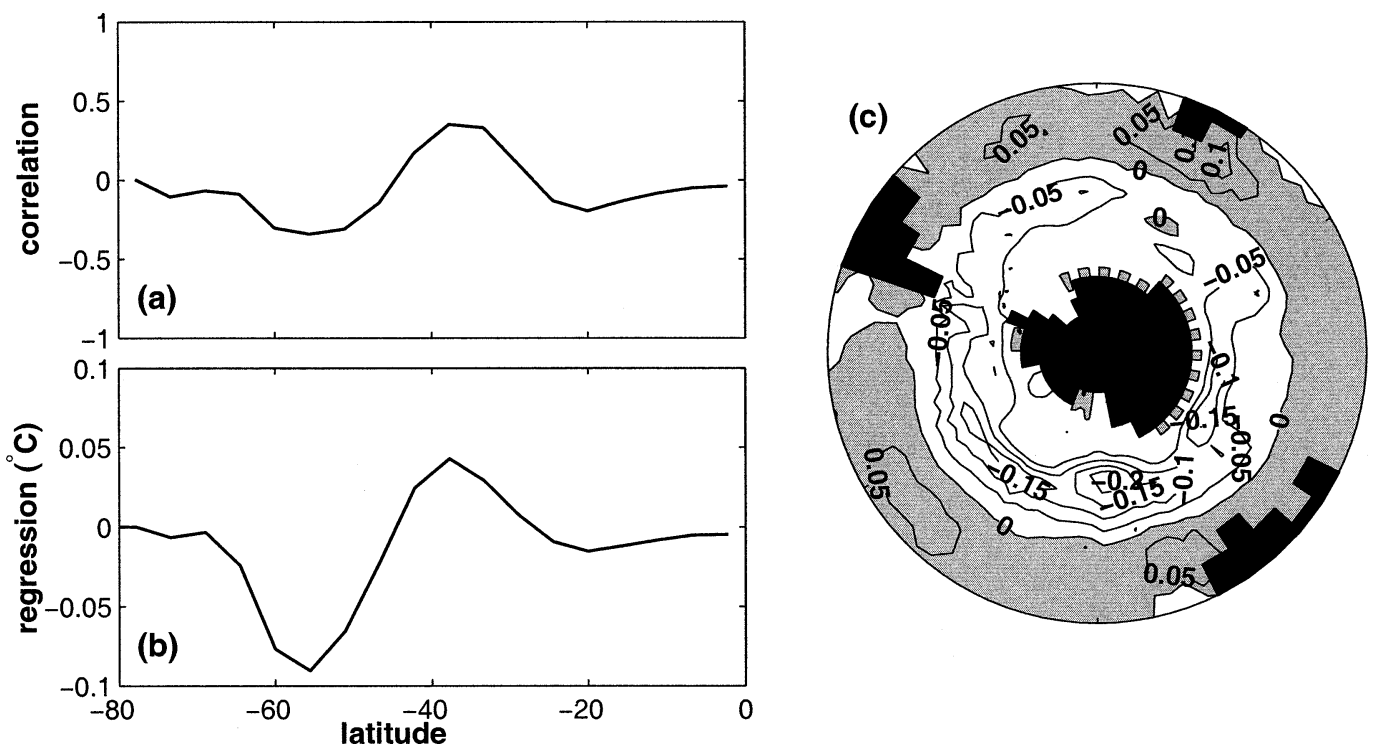

FIG. 9. (a) Correlation between zonal-mean, annual-mean SST and the annual-mean SAM index throughout the SH. (b) Same as (a), except regression coefficients are shown. (c) The regression of annual-mean SST onto the annualmean SAM index throughout the circumpolar region.

the SH is greatest during this half of the year. When sea ice reaches its seasonal minimum during late $\mathrm{SH}$ summer and early fall months, ice extent is reduced nearly to the margins of the Antarctic continent in both model and observations, and is barely affected by the open-ocean Ekman drift anomalies forced by the SAM.) As ice is advected northward during positive SAM, ice thickness decreases near the coast of Antarctica and increases farther north. The correlations with the SAM are modest in most places, with the possible exception of the South Indian Ocean Basin, where correlations reach values as high as 0.4 . Since the current anomalies are so well correlated with the SAM (Fig. 5c), this indicates that local sea ice thickness is mostly determined not by current anomalies, but by local thermodynamic processes.
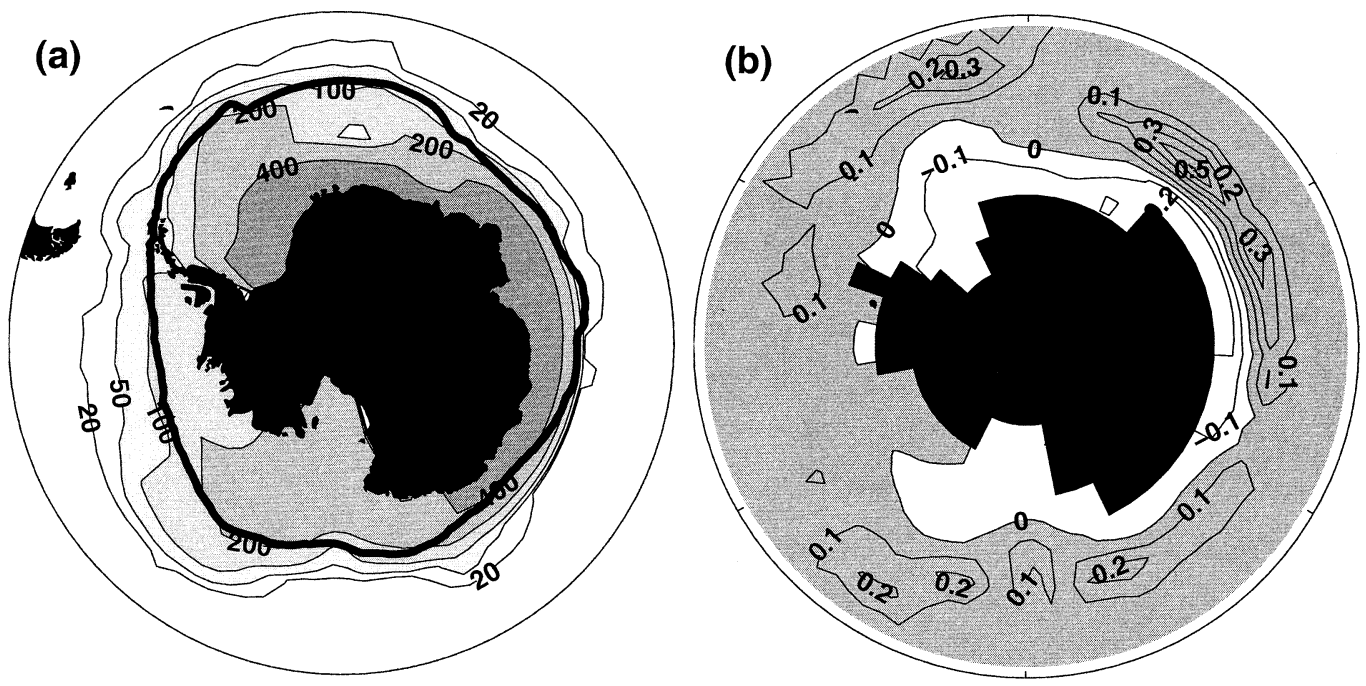

FIG. 10. (a) Climatological mean simulated and observed sea ice averaged over JJASON. The simulated sea ice field is quantified in terms of sea ice thickness $(\mathrm{cm})$ and is shown with thin black contours and gray shading. The observed sea ice field is quantified in terms of ice concentration. The contour corresponding to $30 \%$ ice concentration is shown with a thick line. Observed ice concentrations were obtained from Yuan and Martinson (2000). Because of the difference between model and observation in the way sea ice amount is quantified, it is impossible to make a definitive comparison between the two. Still, (a) shows that the model has sea ice in approximately the same locations as the observations with approximately the same areal coverage of sea ice. (b) The correlation between JJASON simulated sea ice thickness and the JJASON SAM index. 
(a) shortwave

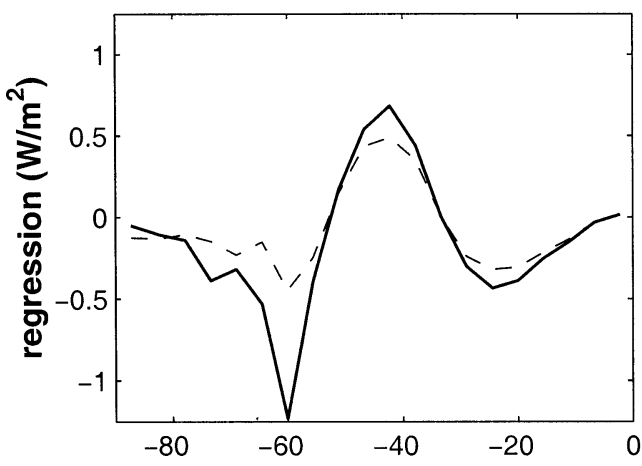

(c) net radiation

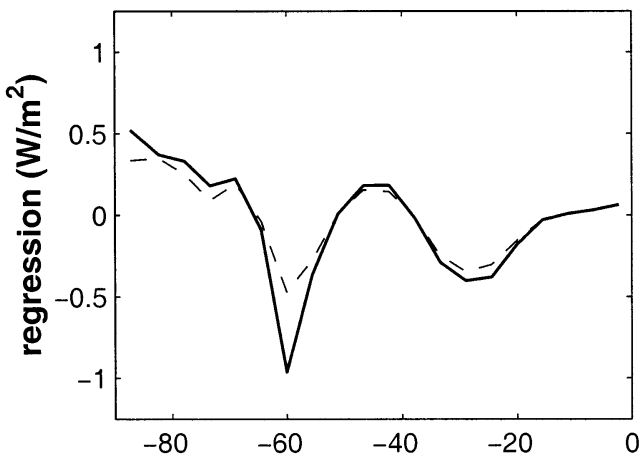

(b) longwave

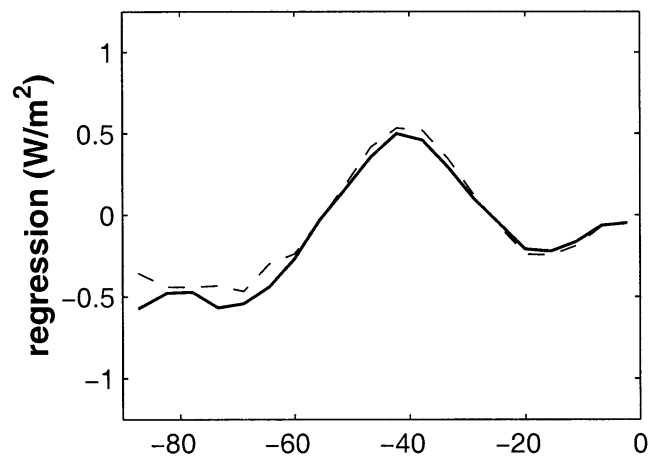

(d) total cloudiness

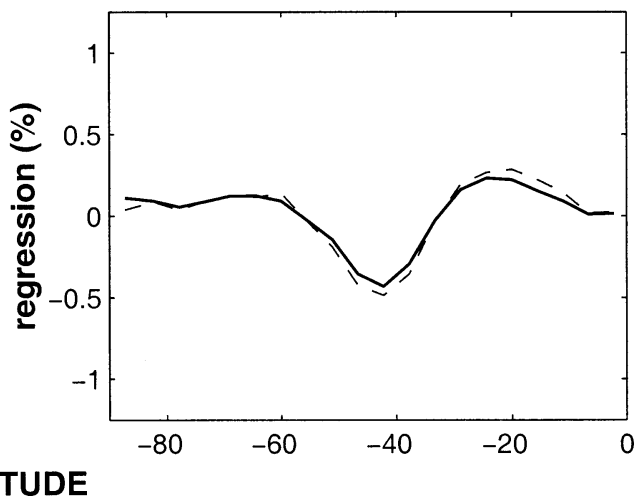

FIG. 11. The regression of annual-mean, zonal-mean atmospheric quantities onto the annual-mean SAM index (solid lines). Correlation coefficients between the two time series are also shown as dashed lines. (a) Net incoming shortwave radiation at the top of the atmosphere. (b) Net outgoing longwave radiation at the top of the atmosphere. (c) Net incoming radiation (shortwave - longwave) at the top of the atmosphere. (d) Total cloudiness, measured by the percent of time the sky is covered by cloud.

It is possible that the sea ice pattern associated with the SAM occurs because sea ice anomalies are generating SAM variability. However, this seems unlikely, because the sea ice pattern of Fig. 10b is so obviously related to the ocean current anomaly pattern of Fig. 5b, which itself is almost certainly forced by the SAM.

While the correlation pattern shown in Fig. 10 shows that the SAM has only a modest impact on local ice thickness variability, the high degree of zonal symmetry in the pattern suggests that the impact on total areal ice coverage might be more significant. To examine this issue, we created an ice coverage time series, defining the ice margin as the location where ice thickness falls below $50 \mathrm{~cm}$. The correlation between the JJASON SAM index and this time series is 0.51 , implying that the SAM accounts for a large share of the simulated variability in total sea ice coverage. The regression of the ice coverage time series onto the SAM index is 5.9 $\times 10^{5} \mathrm{~km}^{2}$, as compared to a total mean ice coverage of $167.4 \times 10^{5} \mathrm{~km}^{2}$. Even a relatively weak 1 sigma anomaly in the SAM is associated with a significant increase in sea ice coverage.

A study of the observed relationship between sea ice and the SAM is beyond the scope of this paper. Such a study would be difficult as continuous multiyear sea ice and surface pressure observations in the SH poleward of $45^{\circ} \mathrm{S}$ are still somewhat sparse, though recent satellite observations of sea ice have improved the observational record. However, statistically significant relationships between NH sea ice and the NAM have been documented using the much better meteorological and oceanographic time series of the NH (Kwok and Rothrok 1999; Kwok 2000). Given this observational evidence from the $\mathrm{NH}$ and the modeling evidence presented in this paper, it seems likely that statistically significant relationships between $\mathrm{SH}$ sea ice and the SAM will eventually also be found in the observations.

Because of the high albedo of sea ice compared to the open ocean, we also examined the possibility that the SAM influences the total radiative budget of the atmosphere through its effect on sea ice coverage. Figure 11a confirms that zonal-mean net incoming shortwave radiation (ISR) is reduced by about $1 \mathrm{~W} \mathrm{~m} \mathrm{~m}^{-2}$ around the latitude of the sea ice margin for a 1 sigma positive anomaly in the SAM. Figure $11 \mathrm{~b}$ shows how this anomaly compares to the SAM's effect on the other 


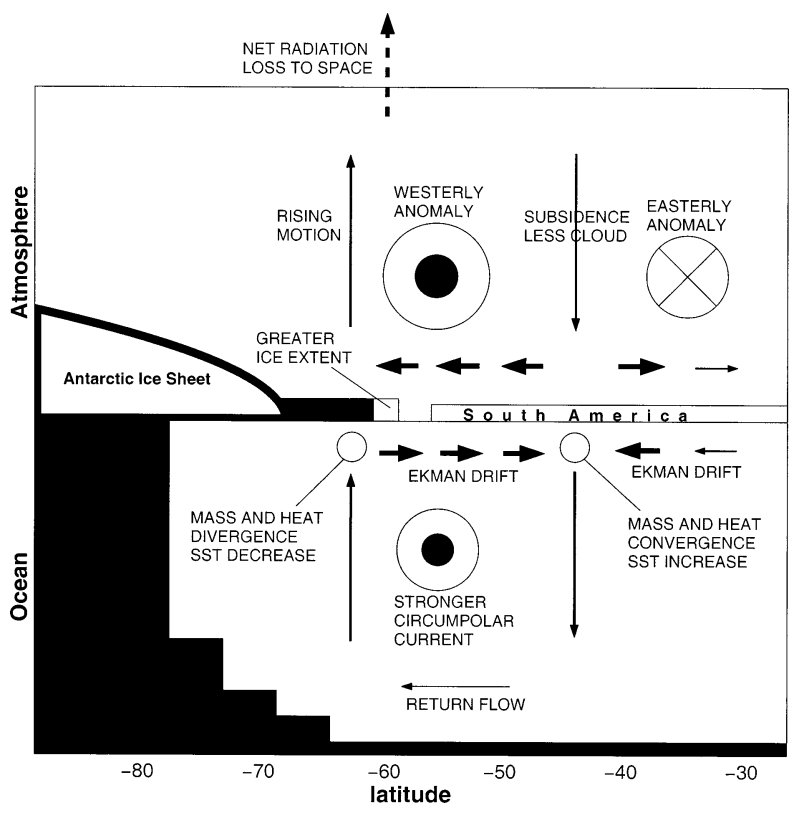

FIG. 12. Schematic drawing of the changes in the atmosphere and ocean that occur when the SAM index is positive.

element of the earth's radiative budget—outgoing longwave radiation (OLR). The SAM is associated with a $0.5 \mathrm{~W} \mathrm{~m}^{-2}$ increase in the OLR at about $40^{\circ} \mathrm{S}$, and an decrease of about the same amount poleward of $60^{\circ} \mathrm{S}$. The OLR increase at $40^{\circ} \mathrm{S}$ can be accounted for by a decrease in clouds (Fig. 11d). The clouds decrease at this latitude because of a poleward migration of the jet stream, and a likely reduction in baroclinic activity and rising motion in consequence (Fig. 3f). The increase in ISR at $40^{\circ} \mathrm{S}$ is also attributable to this loss of cloud. The changes in ISR and OLR almost counterbalance one another in the net radiative budget at $40^{\circ} \mathrm{S}$ (Fig. 11c), so that the dominant feature of the SAM impact on zonal-mean net radiation is a decrease in net radiation at $60^{\circ} \mathrm{S}$, which results from the expansion of sea ice coverage.

\section{Summary}

To summarize our findings, we created a schematic drawing of the changes in the atmosphere and ocean that occur when the SAM rises 1.5 standard deviations higher than its mean value (Fig. 12). As a companion to Fig. 12, we provide a table showing the magnitude of the changes depicted in the drawing, as well as the correlation between these variables and the SAM index (Table 1). For reference, the mean values of the variables are also given in Table 1.

In the atmosphere, positive SAM is associated with a poleward movement and intensification of the atmospheric jet stream. This results in an intensification of the westerlies at about $55^{\circ} \mathrm{S}$ and a weakening at about $35^{\circ} \mathrm{S}$. Frictional meridional flow at the surface is generated by the zonal wind fluctuations. Based on the correlation coefficients in Table 1 [rows (a)-(d)], the SAM accounts for nearly all the variability in zonal-mean surface winds at these locations. In magnitude, the anomalies are about $20 \%$ of their mean values. The surface meridional flow anomalies result in divergence around $40^{\circ} \mathrm{S}$, and convergence at around $65^{\circ} \mathrm{S}$. To satisfy mass continuity, subsidence occurs around $40^{\circ} \mathrm{S}$, while rising motion occurs at around $65^{\circ} \mathrm{S}$. This vertical motion may also be the signature of the poleward migration of baroclinic eddy activity due to the poleward movement of the jet stream.

The ocean receives information about the state of the

TABLE 1. The middle columns show the zonal-mean values of the climatic variables shown in Fig. 12 and the anomaly in those variables typically associated with a $1.5 \mathrm{std}$ dev positive anomaly in the SAM index. The magnitude of the SAM index exceeds 1.5 std dev approximately once every 7 yr. The last column shows the correlation between those variables and the SAM index. Rows (a) $-(\mathrm{g})[(\mathrm{h})-(\mathrm{g})]$ are climatic variables associated with the atmosphere (ocean).

\begin{tabular}{|c|c|c|c|}
\hline Quantity & Zonal mean value & $\begin{array}{c}\text { Anomaly associated with } \\
+1.5 \sigma_{\mathrm{SAM}}\end{array}$ & $\begin{array}{l}\text { Correlation with } \\
\text { SAM index }\end{array}$ \\
\hline (a) Surface zonal winds $\left(55.6^{\circ} \mathrm{S}\right)$ & $3.87 \mathrm{~m} \mathrm{~s}^{-1}$ & $0.85 \mathrm{~m} \mathrm{~s}^{-1}$ & 0.95 \\
\hline (b) Surface meridional winds $\left(55.6^{\circ} \mathrm{S}\right)$ & $-0.94 \mathrm{~m} \mathrm{~s}^{-1}$ & $-0.24 \mathrm{~m} \mathrm{~s}^{-1}$ & -0.94 \\
\hline (c) Surface zonal winds $\left(33.3^{\circ} \mathrm{S}\right)$ & $1.40 \mathrm{~m} \mathrm{~s}^{-1}$ & $-0.31 \mathrm{~m} \mathrm{~s}^{-1}$ & -0.76 \\
\hline (d) Surface meridional winds $\left(33.3^{\circ} \mathrm{S}\right)$ & $-0.31 \mathrm{~m} \mathrm{~s}^{-1}$ & $0.11 \mathrm{~m} \mathrm{~s}^{-1}$ & 0.75 \\
\hline (e) Vertical motion $\left(64.5^{\circ} \mathrm{S}\right)$ & $-75.4 \times 10^{-6} \mathrm{hPa} \mathrm{s}^{-1}$ & $-8.4 \times 10^{-6} \mathrm{hPa} \mathrm{s}^{-1}$ & -0.50 \\
\hline (f) Vertical motion $\left(42.2^{\circ} \mathrm{S}\right)$ & $-13.7 \times 10^{-6} \mathrm{hPa} \mathrm{s}^{-1}$ & $10.2 \times 10^{-6} \mathrm{hPa} \mathrm{s}^{-1}$ & 0.71 \\
\hline (g) Net radiation (ice edge, $60.0^{\circ} \mathrm{S}$ ) & $-61.9 \mathrm{~W} \mathrm{~m}^{-2}$ & $-1.4 \mathrm{~W} \mathrm{~m}^{-2}$ & -0.47 \\
\hline (h) Meridional surface flow $\left(60.0^{\circ} \mathrm{S}\right)$ & $0.68 \mathrm{~cm} \mathrm{~s}^{-1}$ & $0.21 \mathrm{~cm} \mathrm{~s}^{-1}$ & 0.96 \\
\hline (i) Meridional surface flow $\left(33.3^{\circ} \mathrm{S}\right)$ & $0.127 \mathrm{~cm} \mathrm{~s}^{-1}$ & $-0.081 \mathrm{~cm} \mathrm{~s}^{-1}$ & -0.76 \\
\hline (j) Vertical motion (surface, $62.2^{\circ} \mathrm{S}$ ) & $27.7 \times 10^{-6} \mathrm{~cm} \mathrm{~s}^{-1}$ & $11.5 \times 10^{-6} \mathrm{~cm} \mathrm{~s}^{-1}$ & 0.86 \\
\hline (k) Vertical motion (surface, $44.5^{\circ} \mathrm{S}$ ) & $74.4 \times 10^{-6} \mathrm{~cm} \mathrm{~s}^{-1}$ & $-9.7 \times 10^{-6} \mathrm{~cm} \mathrm{~s}^{-1}$ & -0.84 \\
\hline (1) $\mathrm{SH}$ ice coverage & $167.4 \times 10^{5} \mathrm{~km}^{2}$ & $8.9 \times 10^{5} \mathrm{~km}^{2}$ & 0.51 \\
\hline (m) Transport through Drake Passage & $76.1 \mathrm{~Sv}$ & $0.95 \mathrm{~Sv}$ & 0.49 \\
\hline (n) Heat transport $\left(51.1^{\circ} \mathrm{S}\right)$ & $-0.198 \mathrm{PW}$ & $0.038 \mathrm{PW}$ & 0.60 \\
\hline (o) Heat transport $\left(33.3^{\circ} \mathrm{S}\right)$ & $-0.644 \mathrm{PW}$ & $-0.094 \mathrm{PW}$ & -0.69 \\
\hline (p) SST $\left(55.6^{\circ} \mathrm{S}\right)$ & $1.84^{\circ} \mathrm{C}$ & $-0.14^{\circ} \mathrm{C}$ & -0.34 \\
\hline (q) $\operatorname{SST}\left(37.8^{\circ} \mathrm{S}\right)$ & $14.3^{\circ} \mathrm{C}$ & $0.063^{\circ} \mathrm{C}$ & 0.35 \\
\hline
\end{tabular}


$\mathrm{SH}$ atmosphere's annular mode mainly through frictional transfer of momentum at the air-sea interface. The surface westerly anomalies associated with positive SAM excite northward Ekman flow from about $45^{\circ}$ to $65^{\circ} \mathrm{S}$, while the surface easterly anomalies generate southward Ekman drift from $30^{\circ}$ to $45^{\circ} \mathrm{S}$. These surface current anomalies are one- to two-thirds as large as their mean value. To satisfy mass continuity, a $40 \%$ increase in upwelling occurs around the Antarctic coast, while a $15 \%$ decrease in upwelling takes place at about $45^{\circ} \mathrm{S}$. The anomalous flow diverging from the Antarctic continent also increases the vertical tilt of the isopycnals in the Southern Ocean, so that a more intense circumpolar current is also associated with positive SAM: A 1.5 sigma SAM anomaly increases the simulated transport through the Drake Passage by about 1 Sverdrup (Sv; where $1 \mathrm{~Sv} \equiv 10^{6} \mathrm{~m}^{3} \mathrm{~s}^{-1}$ ). In addition, the anomalous divergent flow advects sea ice farther north, resulting in an about a 5\% increase in sea ice coverage. Meridional heat transport is also affected: increases in poleward heat transport of approximately $15 \%$ occur at about $30^{\circ} \mathrm{S}$, while $20 \%$ decreases occur in the circumpolar region. The anomalies in meridional heat transport create heat convergence at about $40^{\circ} \mathrm{S}$ and heat divergence at about $55^{\circ} \mathrm{S}$. This generates modest SST anomalies at these locations. As the correlations listed in the final column of Table 1 indicate, a major fraction of large-scale zonal-mean ocean variability poleward of $30^{\circ} \mathrm{S}$ can be related to the SAM. The variability in ocean circulation is particularly coherent with the SAM.

\section{The potential role of the SAM in climate}

To evaluate the significance of these results, one must first assess the realism of the model. Its coarse resolution is potentially its most serious shortcoming. However, as noted in section 3, the resolution of the model atmosphere is high enough to simulate a SAM very similar to its observed counterpart, both in its spatial structure and its share of overall atmospheric variability. For the purposes of this study, the atmospheric model therefore does a reasonable job of providing the ocean with realistic forcing, in spite of its coarse resolution. In the ocean, the most obvious implication of the model's coarse resolution is that it cannot simulate mesoscale eddies. Since these eddies interact in significant ways with the circumpolar current, the circumpolar current is probably not realistic in structure or strength. In fact, the simulated mean strength of the circumpolar current (76 Sv) is less than observed estimates. For example, Baker (1982) estimates that the strength of the real circumpolar current is $113 \mathrm{~Sv}$. In addition, the actual Southern Ocean is a site of convection and deep water formation, a process that probably occurs on spatial scales smaller than a model grid box. Though significant amounts of deep water form in the model's Southern Ocean, the model is forced to simulate this process on a much larger spatial scale than the real world, so it seems likely that the spatial structure of simulated deep water formation and convection differs significantly from the real ocean.

These model shortcomings notwithstanding, it is difficult to escape the conclusion that the SAM is a major source of large-scale variability in the actual Southern Ocean. Since the main mode of variability in the real $\mathrm{SH}$ atmosphere is the annular mode, as it is in the model, the main mode of wind stress forcing of the actual Southern Ocean has to be the fluctuations of the surface westerlies. The details of the real ocean's response to this forcing have yet to be revealed; but the ocean model's response_Ekman drift at all longitudes_-is exactly the first-order response one would expect. The rest of the impacts (upwelling around Antarctica, downwelling farther north, increases in the strength of the circumpolar current, etc.) are similarly consistent with known and widely accepted principles of $\mathrm{SH}$ ocean dynamics. These mechanisms are unlikely to be significantly affected by the model shortcomings identified above.

We have demonstrated that SH geography facilitates an in-phase, zonally symmetric oceanic response to a zonally symmetric mode of atmospheric variability. Viewing the SH atmosphere and ocean as a synchonously varying, zonally symmetric system from the top of the atmosphere down to the ocean bottom constitutes a significant step toward understanding what controls internal variability in the $\mathrm{SH}$. How might this idea fit in with previous ideas about $\mathrm{SH}$ climate variability? Two main ideas have been proposed previously. First, a series of papers have been published documenting the existence in the observations of an Antarctic circumpolar wave. This wave is characterized by eastward-propagating anomalies in surface pressure, temperature, wind, and sea ice extent on timescales of 4-5 yr (White and Peterson 1996; White et al. 1998). Second, Yuan and Martinson (2000) show statistical relationships between the ENSO phenomenon and Antarctic sea ice extent, implying that perhaps ENSO forces variability in this region. Of course, the Antarctic circumpolar wave and the links between Antarctic sea ice and ENSO may be robust. However, given the overwhelming dominance of the annular mode of the real atmosphere's internal variability on all timescales longer than a few days and the favorable geometry of the SH ocean, it seems likely that when adequate observations of all ocean variability in this region exist, most of the the variability will ultimately be traced not to the Antarctic circumpolar wave or ENSO but to the SAM.

The tendency toward covariability of the atmosphere and ocean in this part of the world is even more significant in light of the accumulating evidence that the atmosphere responds to external forcing in patterns that resemble the SAM. For example, Fyfe et al. (1999) and Kushner et al. (2001) provide modeling evidence that the response of the $\mathrm{SH}$ atmosphere to anthropogenic forcing projects strongly onto the SAM. D. W. J. Thompson and S. Solomon (2002, personal communi- 
cation) attribute recent trends in sea level pressure that resemble the SAM pattern to changes in stratospheric chemistry. And finally, Hall et al. (2002, unpublished manuscript) demonstrate that the SAM-like patterns in surface pressure are preferentially excited by Milankovitch forcing. Thus from interannual to multimillennial timescales, the $\mathrm{SH}$ atmosphere tends to respond to external forcing in a way that looks like the SAM. If it is possible to understand the response of the $\mathrm{SH}$ atmosphere to external forcing in terms of the SAM, then perhaps our results provide a way to understand the response of the SH ocean to external forcing as well.

Finally, it is worth noting the significance of our results for ocean biogeochemistry. Upwelling of deep water around the coast of Antarctica and its subsequent movement to the north is the principal means of nutrient supply for organisms living in the surface waters of the circumpolar ocean. This upwelling also results in significant outgassing of $\mathrm{CO}_{2}$ to the atmosphere when dissolved $\mathrm{CO}_{2}$ stored in the deep ocean water comes in contact with the atmosphere. Any changes in the strength of upwelling and the divergence of ocean water from the Antarctic continent, such as those excited by SAM forcing, would therefore be expected to alter the supply of nutrients to the circumpolar ocean and the rate at which the Southern Ocean releases $\mathrm{CO}_{2}$ to the atmosphere. The fluctuations of the SAM, whether internally generated or externally forced, may have direct implications not only for marine life in the Southern Ocean, but also for the regulation of global atmospheric $\mathrm{CO}_{2}$ levels.

Acknowledgments. The authors wish to thank Ron Stouffer of the Geophysical Fluid Dynamics Laboratory for providing access to the model data, as well as John Fyfe and an anonymous reviewer for constructive criticism of the manuscript. The observed sea ice edge data shown in Fig. 10a were derived from SMMR/SSMI ice concentration data provided by the National Snow Ice Data Center, University of Colorado, Boulder, Colorado. This work is supported by NSF Grant ATM 00-02833. Alex Hall was also partly supported by a Lamont-Doherty Postdoctoral Fellowship while this work was carried out.

\section{REFERENCES}

Baker, D. J., 1982: A note on the Sverdrup balance in the Southern Ocean. J. Mar. Res., 40, 21-26.

Broccoli, A. J., and S. Manabe, 1992: The effects of orography on midlatitude Northern Hemisphere dry climates. J. Climate, 5, $1181-1201$.
Bryan, K., 1969: Climate and the ocean circulation: III. The ocean model. Mon. Wea. Rev., 97, 806-827.

_ , and L. Lewis, 1979: A water mass model of the world ocean. J. Geophys. Res., 84 (C5), 2503-2517.

DeWeaver, E., and S. Nigam, 2000a: Do stationary waves drive the zonal-mean jet anomalies of the northern winter? J. Climate, 13, $2160-2176$

—_ and - 2000b: Zonal-eddy dynamics of the North Atlantic Oscillation. J. Climate, 13, 3893-3914.

Fyfe, J. C., G. J. Boer, and G. M. Flato, 1999: The Arctic and Antarctic Oscillations and their projected changes under global warming. Geophys. Res. Lett., 26, 1601-1604.

Gill, A. E., and K. Bryan, 1971: Effects of geometry on the circulation of a three-dimensional Southern Hemisphere ocean model. DeepSea Res., 18, 685-721.

Gordon, C. T., and W. Stern, 1982: A description of the GFDL Global Spectral Model. Mon. Wea. Rev., 110, 625-644.

Hartmann, D. L., and F. Lo, 1998: Wave-driven zonal flow vacillation in the Southern Hemisphere. J. Atmos. Sci., 55, 1303-1315.

James, I. N., and P. M. James, 1992: Spatial structure of ultra-low frequency variability of the flow in a simple atmospheric circulation model. Quart. J. Roy. Meteor. Soc., 118, 1211-1233.

Kushner, P., I. Held, and T. Delworth, 2001: Southern Hemisphere atmospheric circulation response to global warming. J. Climate, 14, 2238-2249.

Kwok, R., 2000: Recent changes in Arctic Ocean sea ice motion associated with the North Atlantic Oscillation. Geophys. Res. Lett., 27, 775-778.

- and D. A. Rothrock, 1999: Variability of Fram Strait ice flux and North Atlantic Oscillation. J. Geophys. Res., 104 (C3), $5177-5189$.

Lee, S., and S. Feldstein, 1996: Mechanisms of zonal index evolution in a two-layer model. J. Atmos. Sci., 53, 2232-2246.

Limpasuvan, V., and D. L. Hartmann, 1999: Eddies and the annular modes of climate variability. Geophys. Res. Lett., 26, 3133-3136.

_ , and — 2000: Wave-maintained annular modes of climate variability. J. Climate, 13, 4414-4429.

MacDonald, A. M., and C. Wunsch, 1996: An estimate of global ocean circulation and heat fluxes. Nature, 382, 436-439.

Manabe, S., and D. G. Hahn, 1981: Simulation of atmospheric variability. Mon. Wea. Rev., 109, 2260-2286.

—, R. J. Stouffer, M. Spelman, and K. Bryan, 1991: Transient responses of a coupled ocean-atmosphere model to gradual changes of atmospheric $\mathrm{CO}_{2}$. Part I: Annual-mean response. $J$. Climate, 4, 785-817.

Marotzke, J., and P. Stone, 1995: Atmospheric transports, the thermohaline circulation, and flux adjustments in a simple coupled model. J. Phys. Oceanogr., 25, 1350-1364.

Robinson, W. A., 1996: Does eddy feedback sustain variability in the zonal index? J. Atmos. Sci., 53, 3556-3569.

Thompson, D. W. J., and J. M. Wallace, 2000: Annular modes in the extratropical circulation. Part I: Month-to-month variability. $J$. Climate, 13, 1000-1016.

White, W. B., and R. G. Peterson, 1996: An Antarctic circumpolar wave in surface pressure, wind, temperature, and sea ice extent. Nature, 380, 699-702.

— , S. C. Chen, and R. G. Peterson, 1998: The Antarctic circumpolar wave: A beta effect in ocean-atmosphere coupling over the Southern Ocean. J. Phys. Oceanogr., 28, 2345-2361.

Yu, J. Y., and D. L. Hartmann, 1993: Zonal flow vacillation and eddy forcing in a simple GCM of the atmosphere. J. Atmos. Sci., 50, 3244-3259.

Yuan, X., and D. G. Martinson, 2000: Antarctic sea ice extent variability and its global connectivity. J. Climate, 13, 1697-1717. 